\title{
A Longitudinal Study for Types and Changes of Students' Mathematical Disposition
}

\author{
Su-Wei Lin, Wen-ChunTai* \\ Department of Education, National University of Tainan, Taiwan
}

Copyright $(2016$ by authors, all rights reserved. Authors agree that this article remains permanently open access under the terms of the Creative Commons Attribution License 4.0 International License

\begin{abstract}
Mathematical disposition could influence learning and performance, they usually determine how well students motivate themselves and persevere in the face of difficulties, and they influence the choices-making about coursework, and even educational and career paths. The aim of this study is to investigate the same students' mathematical disposition types and changes from $6^{\text {th }}$ grade to $8^{\text {th }}$ grade, and examine the relationship between mathematical disposition and mathematics achievement. The results showed that students' math disposition can be classified into three kinds of leaning orientation: give-up, peer-cooperative for mastery, and self-regulated for mastery. The students possessing the orientation of self-regulated for mastery perform best, followed by peer-cooperative for mastery, and give-up students perform weakest. The variance explained by the types of mathematical disposition in 6 th grade is about $7 \%$. While the students promoted to 8 th grade, these three types of students still have the same pattern in mathematics achievement, the variance explained is about $5 \%$. To examine the changes of mathematical disposition from $6^{\text {th }}$ to $8^{\text {th }}$ grade, there were three kinds of disposition change pattern: High and stable, moderate and stable, and decline. Only about $7.4 \%$ of students are the decline, most students' mathematical dispositions are quite stable across 3 years, especially the self-regulated for mastery and the peer-cooperative for mastery. This study proved the relationship between the students' mathematical disposition and achievement. This suggests that mathematics educators need to focus not just on the development of math knowledge and skills, but on the development of the mathematics disposition.
\end{abstract}

Keywords Longitudinal Study, Mathematics Achievement, Mathematical Disposition

\section{Introduction}

In this constantly increasing and updating knowledge generation, it is important to prompt people still keep learning after completing school education in order to face the problems and challenges of life. This kind of learning is based on basic school education. People have basic knowledge and skills, then they are able to filter and grasp information to solve the problem effectively and fluently. Mathematics is one of the important subjects of school education, with emphasis on logical thinking and problem-solving training. Mathematics is the foundation of science, technology, and engineering. So this study focuses on exploring the mathematics learning of children.

In Taiwan, mathematics has always been valued during the phase of compulsory education. In past decades, mathematics education focus on the emphasis on the learning of cognitive mathematics knowledge and skills previously, now gradually realized the mathematics disposition, such as perception, attitudes, emotions, motivation, goal orientation of mathematics learning will affect the performance of students in mathematics and the future learning or career. De Corte [1] integrated view of some scholars, proposed the effective learning process is characterized the following: learning is constructed, learning is cumulative, learning is self-regulated, learning is goal oriented, learning is situated, learning is cooperative, and learning is individually different. From these aspects, learning arises from the long-term interaction with the surrounding environment, people and things, and the need to have goals and spontaneous learning behavior monitoring as a learning backing, in order to effectively acquire knowledge and skills. Therefore, students' disposition on learning should be one of the important issues of mathematics education.

Prepares young people for a lifetime of learning, which is, learning power is quite important. Learning power refers to the collection of psychological traits i.e. dispositions, habits of mind and capacities that enable a person to engage effectively with a variety of learning challenges [2] [3]. The students only have the ability is not enough to be good learners, they also need to have the will to touch learning opportunities. Those students with high levels of learning disposition have the will to be open to learning opportunities, and engaged with the challenges pleasurably 
rather than aversively where they are uncertain of success.

Goal orientation is one of the important constructs of disposition, based on Dweck[4] definition, goal orientation is a "disposition toward developing or demonstrating ability in achievement situations". From the above, students' mathematics learning dispositions and their mathematics performance are related. Mathematics teaching should not only focus on the students' acquisition of mathematical concepts, but also strength for students' mathematics learning disposition. At first, in-depth understanding of the characteristics of students' disposition toward mathematics is required. Considering the features or types of students' dispositions are different, if we could classify the dispositions accurately and objectively, the educators can adopt appropriate and effective approach aimed at developing proficiency for different groups. This study tries to investigate the relationships between learning goal orientation and mathematics achievement over a 3-year period. The first purpose of this study is to find the optimal category mode of students' math learning goal orientation by using the latent class analysis(LCA).The second purpose is to explore the relevance of goal orientation and mathematics achievement, especially for the relationships between different types of goal orientation and students present and future mathematics performance. In addition, current research is less aligned with students' goals orientation for long-term tracking, especially for understanding the change of across different learning phases. For Taiwanese students, the learning in sixth grade to eighth grade are quite different challenges. They go through the different learning from primary school to secondary school level. Face the change to different learning experiences, student goal orientation may vary with the previous. The third purpose of the present study is to investigate the possible patterns of students' goal orientation trends. That is, we are interested in the issue of the students' goal orientation with the growth of learning experience which will change or not. For this purpose, this study adopt the Latent class growth analysis (LCGA) to investigate the optimal latent class growth model of the students' mathematics learning goal orientation from $6^{\text {th }}$ to $8^{\text {th }}$ grade.Finally, the fourth purpose is to explore the possible association between original types and change patterns of math goal orientation. Based on these purposes, this research collected the data of math learning goals and achievements for with a group of students from sixth grade to eighth grade to explore the research questions below:

1. What is the optimal latent class model of sixth grade students' mathematics learning goal orientation?

2. How is the association between different types of math goal orientation and mathematics achievement?

3. What is the optimal latent class growth model of $6^{\text {th }}$ to $8^{\text {th }}$ grade students' mathematics learning goal orientation?

4. How is the association between original types and change patterns of math goal orientation?

\section{Literature Review}

\subsection{Mathematical Dispositions}

Learning disposition is regarded as an important part of modern education, scholars from different angles to explore the learning dispositions. According to the definition of Encyclopedia of the Sciences of Learning ([5], p.1015), disposition refers to "general, relatively stable inclination to approach new learning tasks and situations in a particular way". Katz (1988) points that "dispositions are a very different type of learning from skills and knowledge. They can be thought of as habits of mind, tendencies to respond to situations in certain ways (cite form [3], p.10). The report of National Research Council (NRC), Adding it up: Helping children learn mathematics [6], there are five strands of mathematical proficiency: conceptual understanding, procedural fluency, strategic competence, adaptive reasoning, and productive disposition. The front four is about the ability of the individual, and the last, the productive disposition, is about affection of the individual. In here, productive disposition refers to a "habitual inclination to see mathematics as sensible, useful, and worthwhile, coupled with a belief in diligence and one's own efficacy".

Chen, Hung, Lin, and Wu [7] defined mathematics learning disposition as a cultivated habit of mind or behavioral pattern during the mathematics learning process, which includes the individual's affection characteristic, cognitive performance, and the action tendency of problem situations. Based on their result, there are four types of mathematics being classified: alert-type, accumulative-type, test-focus-type, and evasive-type, these four type students deal with mathematics differently and presented different characteristics in learning mathematics [8]. Claxton and Carr [9] investigated how to enhance the students' positive learning disposition from the aspects of teachers, curriculum and learning environment, so that students can be a ready, willing and able to devote the growth of learning. Birenbaum and Nasser [10] found that there are gender differences in mathematics disposition.

From the above definitions of the disposition of several scholars can learn about the contour of mathematics disposition. In this study, mathematics disposition refers to the individual in the face of mathematics learning, with a particular type of behavioral pattern and mathematical cognitive habits.

\subsection{Goal Orientation of Mathematics Learning}

Dweck and Elliott [11] claim that learners who possess different goals will results have different achievement performance. They identified two classes of students' goal orientation, namely learning goal and performance goal. The individual holds learning goal will pursue the enhancement and mastery of ability, but the individual holding performance goal aims at showing the individual's 
ability to get a good evaluation, or to prevent negative judgment for their ability from others. Students with learning goal orientation appears high persistence and faces challenges pleasurably to improve their competence, is called mastery-oriented students, and the students with performance goal, can be classified as two orientations depending on the degree of confidence of themselves ability, if the students possess high degree of confidence about their own ability, they usually have a high degree of perseverance and looking for a challenge, belonging to mastery orientation; on the contrary, if they have no confidence in the ability of the moment, then will avoid the challenge and have low perseverance, is called helpless students [4] [11].

Compare to the classification of Dweck and Elliott, lots of researchers classified students' goal orientation into three categories, learning or mastery goal orientation, performance or ego orientation, and work avoidant goal orientation. Those who are classified work avoidant goal orientation usually have no will to engage in the academic activities ([12], p. 7). Pintrich [13] integrated the goal orientation and self-regulated learning, proposed that the mastery and performance goal orientation also may be divided into approach and avoid components. For example, the learner with mastery-approach goal value the learning process, use more self-regulation strategy, and have more positive motivation and belief; the students hold mastery-avoidance goals work to avoid misunderstanding, use of standards to not be wrong when doing an achievement activity, perfectionists may be characterized as holding mastery-avoidance goals. Relatively, students who hold performance-avoidance goal usually desire to avoid performing more poorly than others do, and the students with the performance-approach goal usually try to outperform others) [13]. According to the model proposed by above researchers, this study divides students' math learning goal orientation into mastery orientation, performance orientation, and abandon orientation.

\section{Method}

\subsection{Participants and Sampling}

The sixth graders participated in this study since 2011. Participants were from the same county in Taiwan. Since the Department of Education of this county is interested in understanding the students' learning, all students were asked to participate in the summative assessment. Participants took the mathematics achievement tests and questionnaire for three consecutive years. After excluding the incomplete data, there were 2846 students in the analysis of this study.

\subsection{Mathematics Achievement Assessment}

Student's mathematics achievement is estimated from a summative math assessment at the end of the school year.
Students from sixth grade through eighth grade are subject to the summative assessment. The construct of assessments are based on Taiwan Grade 1-9 Curriculum Guidelines. This study collected the students' mathematics achievement of sixth grade to eighth grade and adopted BILOG-MG software for calibrating items and individuals using the one parameter logistic item response theory model.

\subsection{Mathematical Dispositions}

While students taking the summative mathematics achievement assessment, they were also asked to reply the questionnaire of mathematical disposition simultaneously, the questionnaire consists of four questions about mathematics learning goal orientation. Every question of mathematics learning goal orientation has four options, each option corresponds to a different type of learning goal orientation. Data transformed into interval data and through Rasch analysis from Winsteps (Linacre, 2004, version 3.51). Rating scale structure Application of Rasch Measurement was evaluated using category probability curves to determine if mean measures increased as the categories stepped up the scale in the 'more' direction, the higher the value means that students' mathematics learning goal orientation more tend to mastery, the lower tend to abandon or give up.

\subsection{Data Analysis}

This study used latent class analysis (LCA) to analyze the possible patterns of sixth grade students' mathematics learning goal orientation. At first, selected the optimal latent class model of mathematics learning goal orientation by LCA. Then, for the profile of the student's math learning goal orientation in sixth grade through eighth grade, this study used the latent class growth analysis (LCGA) to estimate the change patterns in classification of students' mathematics learning goal orientations. Finally, using correspondence analysis to examine the relationship between the students' math learning goal orientation types in sixth grade and the mathematics learning goal orientation change patterns over 3 years.

LCA is proposed by Lazarsfeld and Henry (1968), it is to identify possible latent classes of categorical variables by observing the responses on these variables, and its main purpose is to make a good classification for the subject, it will present the latent class proportion and conditional probability in the result, latent class proportion is the ratio of the subjects have been assigned to a particular class or group, while the conditional probability representatives the probability of specific response of specific class or group, for example, if the observed variables are binary scoring, the responses of subjects will be either positive or negative, the conditional probability usually shows the probability of positive response of the specific class or group[14].The objective of LCA models is to categorize people into classes by using the observed items associate categorical 
variables. Latent class growth analysis (LCGA) is a particular type of Growth Mixture Model (GMM), but also the easiest longitudinal mixture model, the growth trajectory of the individuals in the same class is the same, no variation [15]. The main purpose of LCGA is to classy individuals by their change traces on a specific variable over time, the individuals with similar changes in trace will be classified into the same class or subgroup in the population.[16] When using LCA and LCGA, the model fit indicators are AIC (Akaike information criterion), BIC (Bayesian information criterion), Adjusted BIC, Entropy, etc. The AIC, BIC and Adjusted BIC values are small, it means that the model is more optimal, if the sample size is large, the BIC should be the main consideration. Entropy stands for the classification correctness of the model; its value is closer to 1 , means the higher classification correctness.

Correspondence analysis (CA) is a kind of multivariate statistical technique, used to explore the relationship between categorical variables, the main purpose is to examine the association between these variables, the results of correspondence analysis is listed a contingency table and correspondence structure of rows and columns is in the form of dots represented in the lower-dimensional space, to present the column and row pairing relationship [17].

\section{Results}

\subsection{Best Fit Model of 6th Grades' of Math Disposition}

The Latent class model data fit indexes of sixth grade students' mathematics learning goal orientation is shown in Table 1. The results show the value AIC and adjusted BIC in the 5-class model is the smallest, and BIC in the 4-class model is the smallest, but Entropy is the lowest. Entropy in the 3-class model is highest. To examine the AIC, BIC and adjusted BIC value changes, the result presented in Figure 1, it suggests that these three indicators after 3-class models tend to be flat, it shows the model data fit improved large from the 2-class model transfer to the 3-class model, but improved quite small after 3-class model further. Therefore, this study adopted the 3-class mode as the optimal model, it means that the sixth-grade students' mathematics learning goal orientations in this study can be divided into three classes.

Table 1. Summary of LCA Criteria in Each Class Model for Sixth Grade Students' Mathematics Learning Goal Orientation

\begin{tabular}{ccccc}
\hline Model & AIC & BIC & adjusted BIC & Entropy \\
\hline 2-class & 28149.95 & 28304.23 & 28224.795 & 0.76 \\
3-class & 27320.46 & 27554.97 & 27434.226 & 0.79 \\
4-class & 27133.47 & 27448.21 & 27286.156 & 0.75 \\
5-class & 27056.23 & 27451.2 & 27247.839 & 0.73 \\
\hline
\end{tabular}

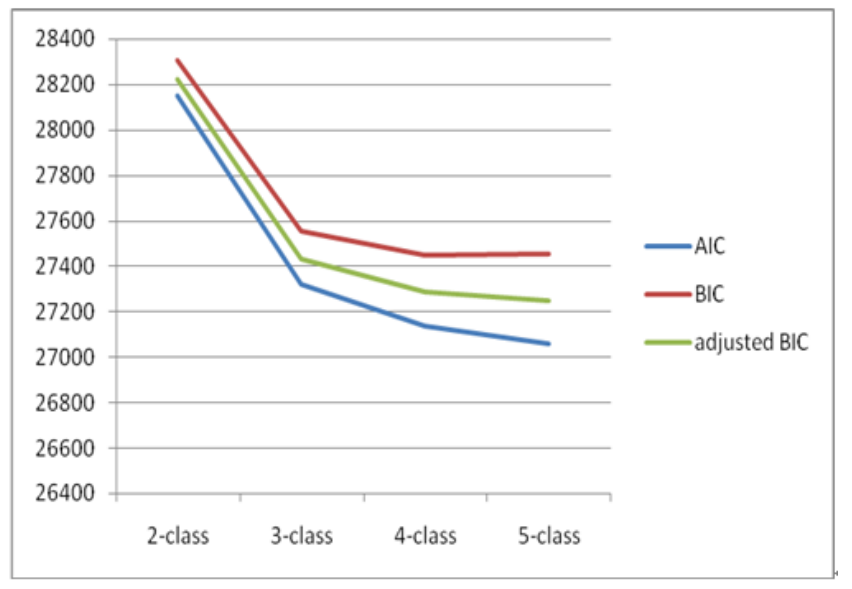

Figure 1. The Changes of AIC, BIC and adjusted BIC from 2- to 5-class

Table 2 presents the conditional probabilities and latent class probabilities based on LCA results. The latent class probabilities stand for the ratios of students to be assigned to various classes, the probability of these three classes were $0.114,0.299,0.586$, that is all $11.4 \%$ of students were assigned to Class $1,29.9 \%$ was assigned to Class 2, and $58.6 \%$ of the students are to be assigned to Class 3. The probability of the Class 1 in the first option on the first question is 0.129 , representing the class of students will choose to answer the first question "willing, I hope to improve my math skills", the probability of this option is $12.9 \%$.

From Table 2 and Figure 2, it can be clearly observed CLASS 1 students than the other two classes of students in the probability of each of these options of mastery or performance are low, but the probabilities of the option of abandoning are higher than the other 2 class. Based on the responses, the CLASS 1 was termed "give-up" group, this group of students in the face of mathematics, have no confidence in their abilities, but also believes that no matter how diligent are useless, they are unwilling to face mathematics, and hold give-up attitude toward mathematics.

The response patterns of CLASS 2 and CLASS 3 are similar in response to the first question and the fourth question. Both classes would like to make their math skills better, and willing to make efforts for progressing. However, these two classes of students in the face the challenge of math problem, their way of solution adopted is different, CLASS 2 students prefer to learn and discuss with classmates, CLASS 3 students tend to think for themselves to solve. In this study, the CLASS 2 students are termed "peer-cooperative for mastery" group, and the CLASS 3 is termed "self-regulated for mastery" group.

\subsection{The Relationship between Goal Orientation and Mathematics Achievement}

Table 3 presents the average math achievement of different types of learning orientation. For the sixth grade students, it suggested the self-regulated for mastery group 
math performance is best, followed by the peer-cooperative for mastery group, and the give-up group is weakest. Using one-way analysis of variance test to examine the differences of group means, the result is shown in Table 4, it suggests that there are statistically significant differences among the group means, $\mathrm{F}(2,2843)=101.132, \mathrm{p}<.001, \eta 2=.07$, the learning oriented type on the sixth graders account for $7 \%$ of the variance of mathematics achievement. The results of multiple comparison showed that it is different about mathematics performance of these three groups from each other, the average math achievement of the group of self-regulated for mastery is better than the other two groups, and the peer-cooperative for mastery group perform better than the give-up group in mathematics.

The relative performance in mathematics is quite stable in 3 years later. Table 5 presents the average math achievement after these three groups grew up to eighth grade. Similar to the situation while they were in sixth grade, the self-regulated for mastery group perform best, followed by the peer-cooperative for mastery group and the give-up group. Table 6 suggests that there still exists statistical significance among the means of these three groups, $\mathrm{F}(2,2843)=71.547, \quad \mathrm{p}<.001, \eta 2=.05$, the strength of association between the independent and dependent variables (i.e. Types of goal orientation and math achievement) is a little decrease to $5 \%$. The results of multiple comparisons also showed there are significant differences of average mathematics achievements among these three groups, the relative performance in eighth grade is the same with in sixth grade.

From the above results, it can be found that the students' mathematics learning goal orientation type in sixth-grade not only affect the mathematics achievement at the same time, this type also account for the variation of math achievement after three years later, though the explanatory power from $7 \%$ to $5 \%$, but overall, the student's math goal orientation is a quite stable factor relate to students' math performance.

Table 2. Conditional Probabilities and Latent Class Probabilities on the Mathematics Learning Goal Orientation Scale for the 3-Class Model

\begin{tabular}{|c|c|c|c|c|}
\hline Item & Orientation & CLASS 1 & CLASS 2 & CLASS 3 \\
\hline \multicolumn{5}{|l|}{$\begin{array}{l}\text { If you were going to do a similar test again two months later, were you willing to } \\
\text { work harder to prepare for it? }\end{array}$} \\
\hline A1.Yes, I was. I hope to improve my math capability. & Mastery & 0.129 & 0.597 & 0.76 \\
\hline A2. Yes, I was. Do not work hard, I will be to blame by my parents & Performance & 0.215 & 0.133 & 0.049 \\
\hline A3. Yes, I was. Do not work hard will be lost to other students. & Performance & 0.192 & 0.246 & 0.18 \\
\hline A4. No, I was not. Efforts to no avail. & Abandon & 0.463 & 0.023 & 0.011 \\
\hline \multicolumn{5}{|l|}{ When you face a math problem that you do not know how to do, how would you do? } \\
\hline B1.I would try to solve it by myself. & Mastery & 0.184 & 0 & 0.755 \\
\hline B2. Wait for teacher's instruction. If the teacher did not teach, this would not test. & Performance & 0.16 & 0.014 & 0.03 \\
\hline B3. Ask classmate. & Mastery & 0.341 & 0.976 & 0.208 \\
\hline B4. Let it go. & Abandon & 0.315 & 0.009 & 0.007 \\
\hline
\end{tabular}

When you face a math problem that you have never seen, how would you do?

C1. Use the methods that teacher recently taught us.

$\begin{array}{cccc}\text { Performance } & 0.117 & 0.166 & 0.338 \\ \text { Mastery } & 0.157 & 0.003 & 0.519 \\ \text { Mastery } & 0.36 & 0.83 & 0.135 \\ \text { Abandon } & 0.365 & 0.002 & 0.008\end{array}$

C2. Work hard to find the problem solving methods.

C3. Ask or discuss with classmates.

C4. Give it up. I must not be able to do the problem that I have never seen.

If you would take the test again, would you progress? Why?

D1.Yes, I would. Because I will work harder, so I would progress.

D2. Yes, I would. Because my math ability is very good. If the test that I have taken before, I would do it correctly next time.

D3. No, I would not. Because my math ability is not good, no matter how diligent is useless.

D4. No, I would not. Because I hate math, I feel very painful, I do not want to face it.

\begin{tabular}{cccc} 
Mastery & 0.09 & 0.699 & 0.809 \\
Performance & 0.144 & 0.137 & 0.148 \\
Abandon & 0.332 & 0.12 & 0.029 \\
Abandon & 0.434 & 0.043 & 0.015 \\
\hline & 0.114 & 0.299 & 0.586
\end{tabular}




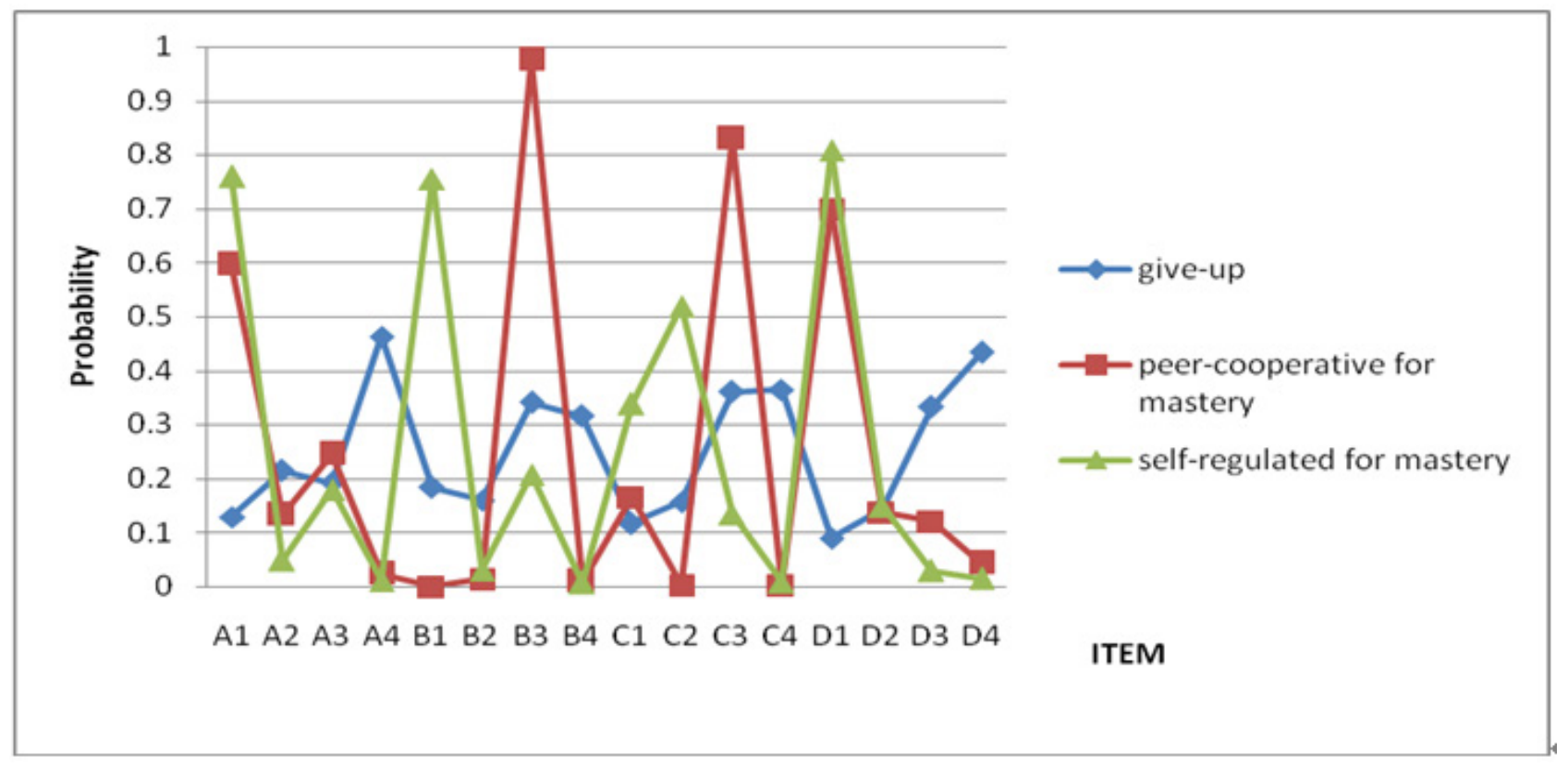

Figure 2. Distribution of Conditional Probabilities of Each Item for the 3-Class Model

Table 3. Descriptive Statistics of Math Achievement of Different type of goal orientation for sixth grade students

\begin{tabular}{cccc}
\hline Class & Mean & SD & $\mathrm{N}$ \\
\hline Give-up & -.532 & .914 & 314 \\
Peer-cooperative for mastery & -.123 & .903 & 850 \\
Self-regulated for mastery & .233 & 1.005 & 1682 \\
\hline Total & .042 & .999 & 2846 \\
\hline
\end{tabular}

Table 4. ANOVA Results of Mathematics Achievement in Sixth Grade for Different Types of Goal Orientation

\begin{tabular}{ccccccc}
\hline Source & SS & df & MS & F & p & $\eta^{2}$ \\
\hline Between & 188.672 & 2 & 94.34 & 101.132 & 0.00 & .07 \\
Within & 2651.964 & 2843 & 0.93 & & & \\
\hline Total & 2840.636 & 2845 & & & & \\
\hline
\end{tabular}

Table 5. Descriptive Statistics of Math Achievement of Different type of goal orientation for eighth grade students

\begin{tabular}{cccc}
\hline Class & Mean & SD & N \\
\hline Give-up & -.431 & .871 & 314 \\
Peer-cooperative for mastery & -.125 & .903 & 850 \\
Self-regulated for mastery & .204 & 1.037 & 1682 \\
\hline Total & .036 & 1.005 & 2846 \\
\hline
\end{tabular}

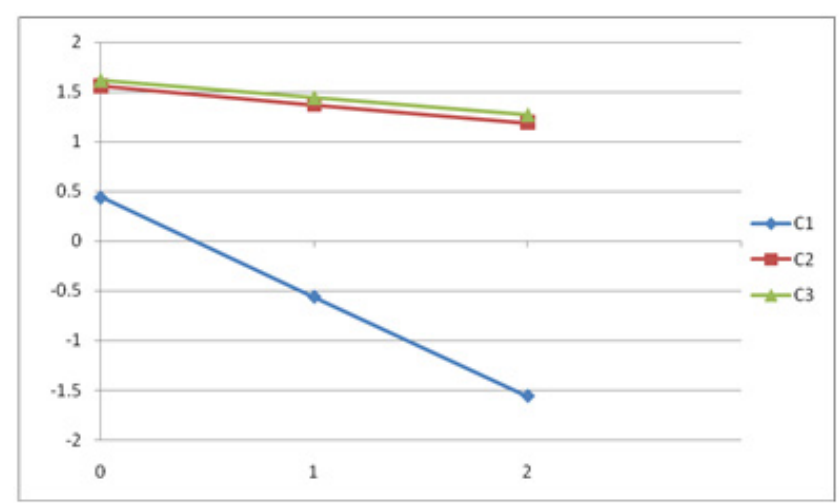

Figure 3. Profile of Goal Orientation of the 3-Class Model of LCGA

Table 6. ANOVA Results of Mathematics Achievement in Eighth Grade for Different Types of Goal Orientation

\begin{tabular}{ccccccc}
\hline Source & SS & df & MS & F & p & $\eta^{2}$ \\
\hline Between & 137.795 & 2 & 68.898 & 71.547 & .000 & .05 \\
Within & 2737.733 & 2843 & .963 & & & \\
Total & 2875.528 & 2845 & & & & \\
\hline
\end{tabular}




\subsection{Change Pattern of Mathematics Learning Goal Orientation over 3 Years}

To explore the change patterns of mathematics learning goal orientation, this study collected the data of the same students' goal orientation reaction for three consecutive years. After using the Rasch model to calibrate this variable over 3 years, this study used LCGA further to explore the possible patterns. The results shown in Table 7, BIC and adjusted BIC proved the 3-class model is the optimal one, while AIC is prefer the 4-class model, but the sample size in this study is large, and the values of BIC and AIC from 3-class drop to 4-class rarely. Therefore, three class model was chosen in this study.

Table 7. Summary of LCGA Criteria in Each Class Model $(\mathrm{N}=2846)$

\begin{tabular}{cccc}
\hline Model & AIC & BIC & adjusted BIC \\
\hline 2-class & 88103.44 & 88186.80 & 88142.31 \\
3-class & 88040.26 & $\mathbf{8 8 1 4 7 . 4 2}$ & $\mathbf{8 8 0 9 0 . 2 3}$ \\
4-class & $\mathbf{8 8 0 3 1 . 9 7}$ & 88162.95 & 88093.05 \\
\hline
\end{tabular}

Table 8 shows the proportion, intercept and slope of the three groups of students' mathematics learning goal orientation changes. Figure 3.Presents the mean of mathematics learning goal orientation over 3 years. The points of 0,1 , and 2 in the horizontal axis represent sixth grade, seventh grade and eighth grade. It can be seen the $\mathrm{C} 2$ and $\mathrm{C} 3$ students start from higher value in mathematics learning goal orientation, and decline slightly, compared to $\mathrm{C} 1$, the change of $\mathrm{C} 2$ and $\mathrm{C} 3$ are stable trend, $\mathrm{C} 3$ initial score slightly higher than $\mathrm{C} 2$, and the slope of $\mathrm{C} 3$ is also slightly higher than $\mathrm{C} 2$, that means that mathematics learning goal orientation value reduced less than $\mathrm{C} 2$, therefore, the $\mathrm{C} 3$ this class is named high and stable, $\mathrm{C} 2$ is named as moderate and stable. The $\mathrm{C} 1$ students' goal orientation clearly declines rapidly year after year, so the $\mathrm{C} 1$ is named decline.

Table 8. Summary of Growth of Goal Orientation for the 3-Class Model

\begin{tabular}{cccc}
\hline Group & Classification of Proportion & Intercept & Slope \\
\hline C1 & $7.40 \%$ & 0.441 & -1 \\
C2 & $89.30 \%$ & 1.558 & -0.185 \\
C3 & $3.30 \%$ & 1.619 & -0.173 \\
\hline
\end{tabular}

\subsection{Relationship between Original Type and Change Pattern of Goal Orientation over 3 Years}

Using the correspondence analysis to examine the relationship between the students' original types and their possible change patterns of mathematics learning goal orientation, the result shows that $\chi 2=136.954, \mathrm{p}<.001$, it means that goal orientation type in sixth grade and the change pattern of goal orientation is not independent. Figure 4 shows the give-up tends to be the decline, the self-regulated for mastery and peer-cooperative for mastery tends to be moderate and stable, and the high and stable is closer to the self-regulated for mastery. In other words, the student's mathematics learning goal orientation is give-up type, her/his mathematics learning goal orientation over 3 -year period tend to decline rapidly; if the student's mathematics learning goal orientation is the self-regulated for mastery or peer-cooperative for mastery, their mathematics learning goal orientation is stable, especially the self-regulated for mastery students, they are more likely to sustain enthusiasm for mathematics learning. 


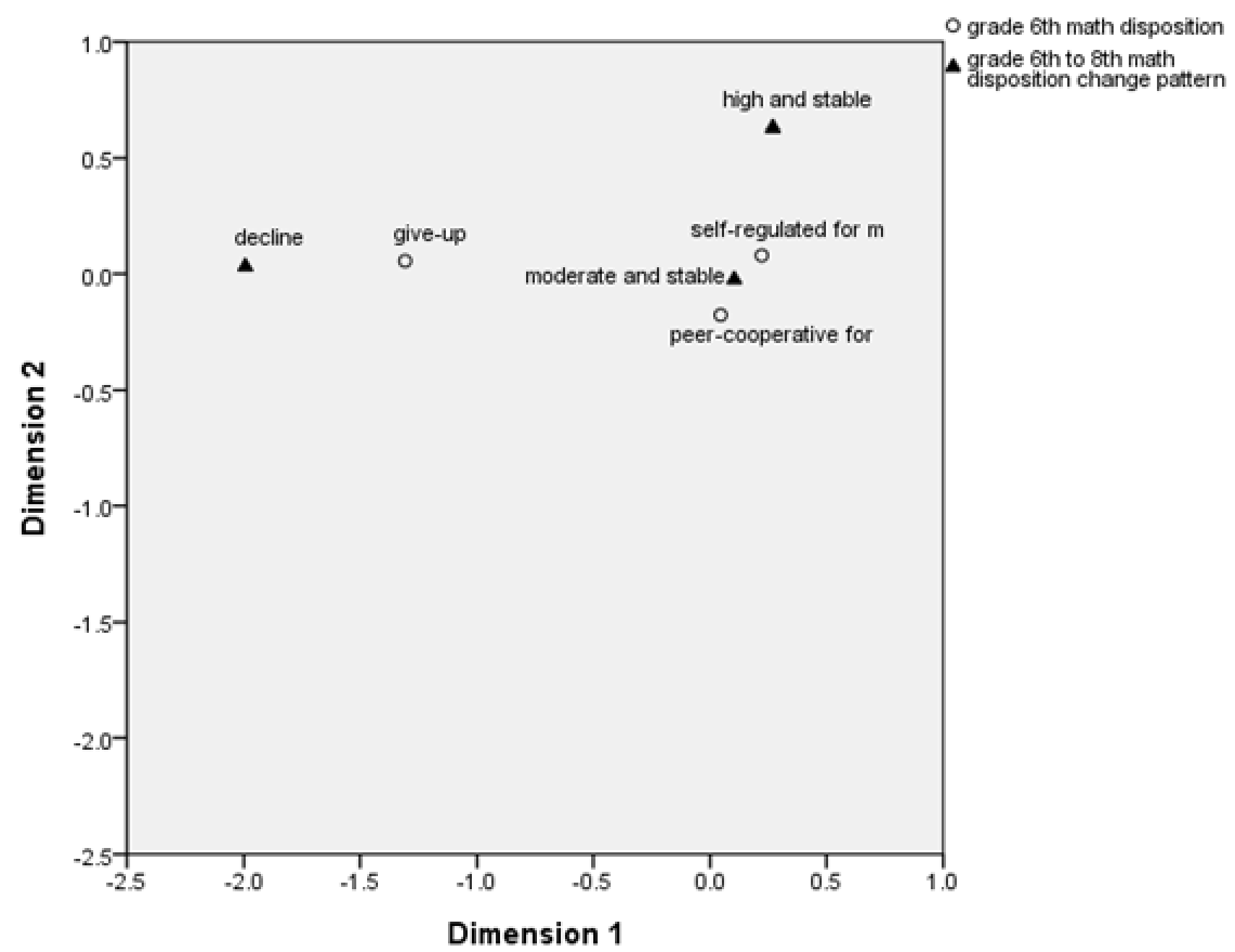

Figure 4. Correspondence of Original Type and Change Patterns of Students' Mathematical Disposition

\section{Conclusions}

Nowadays, facing the rapid development of technology and information, how to face and solve the challenges and problems in daily life, the lifelong learning is an important issue for educators. Students who have a positive and productive learning disposition, they usually have a willingness to engage learning and face the challenges and further solve them. However, the shape of student's learning disposition usually comes from the long term interaction with important other people and things around them. Therefore, to conduct longitudinal research for students learning disposition is necessary.

In this study, three-year longitudinal study to collect information on students' math learning goal orientation, the results of first year show that students in sixth grade, their mathematics learning goal orientation can be divided into give-up, peer-cooperative for mastery, self-regulated for mastery of these three types. About half of the students belong to the type of self-regulated for mastery, these three groups of students in mathematics achievement are different stably over 3 years, the performance of the self-regulated for mastery students is the best, followed by peer-cooperative for mastery, and the give-up is the weakest. In other words, the sixth grade students' mathematics learning goal orientation is related to present and future mathematics achievement.

In addition, examining of student mathematics learning goal orientation change patterns, the results show that most students' mathematics learning goal orientation change is slightly declining from sixth to eighth grade, but the overall slope is quite flat. However, there is a minority group of students' math learning goal orientation lower than the initial state, their profile of goal orientation decline rapidly. To sum up, if students have high and positive goal orientation, they tend to be less likely to have a declining disposition for learning and usually have better performance.

Investigating the students' original type of mathematics learning goal orientation at first year and the change pattern of mathematics learning goal orientation over 3 years, this study showed that the mathematical disposition of the self-regulated for mastery and the peer-cooperative for mastery students, they desire to pursue mathematics mastery, usually have higher values and better able to maintain a positive learning goal orientation. Therefore, 
educators or teachers should notice the students' learning disposition as soon as possible, and endeavor to help students develop the more positive mathematical learning goal orientation. Student learning goal orientation is involved in the mathematics disposition, Crick and Goldspink [18] claimed that learning disposition is "an embodied characteristic that is maintained in and through the learner's engagement with their environment, and reflexively through affective states and self-narrative". The current state of disposition reflects the individual's history, including the wider social and cultural experiences, it influence their being and their beliefs about themselves and learning. Therefore, educators should pay attention to the shaping of students' mathematics learning disposition, and should start as early as possible. Consider from the design of curriculum, interaction with teachers and peers, clear feedback to help students face learning mathematics, enhancement of student's self-efficacy, prevention and improvement of students' learned helplessness. For the peer-cooperative for mastery students, try to encourage them to think of themselves independently before asking or discuss with classmates, spur them to have own depth thinking and solve problems actively.

This longitudinal study tried to investigate the relationships between students' mathematics learning goal orientation and the mathematics achievement over 3 years. The future research could consider other constructs of disposition for learning mathematics to investigate more broadly and deeply. Besides, consider to involve more factors, such as gender, SES, study program etc. to enrich the field of vision and research resources of mathematics education.

\section{REFERENCES}

[1] De Corte, E. (1995) Fostering cognitive growth: A perspective from research on mathematics learning and instruction, Educational Psychologist, $30 \quad$ (1), 37-46, DOI:10.1207/s15326985ep3001_4.

[2] Claxton, G. (1999) Wise Up: the challenge of lifelong learning. London, Bloomsbury.

[3] Carr, M. \& Claxton, G. (2002) Tracking the Development of Learning Dispositions, Assessment in Education: Principles, Policy \& Practice, 9(1), 9-37,DOI:10.1080/096959402201191 48.

[4] Dweck, C. S. (1986). Motivational processes affecting learning. American psychologist, 41 (10), 1040-1048.
[5] Seel, N. M. (Ed.). (2012).Encyclopedia of the Sciences of Learning. Springer Science \& Business Media.

[6] National Research Council. (2001). Adding it up: Helping children learn mathematics. Kilpatrick, J., Swafford,J., \&Findell, B. (Eds.). Mathematics Learning Study Committee, Center for Education, Division of Behavioral and Social Sciences and Education. Washington, DC: National Academy Press.

[7] Chen. C. T., Hung, P. H., Lin C. J. \& Wu, Y. Y.(2008)The Validity Study for the Categorization Criterion of Mathematics Learning Dispositions. Psychological Testing,55(2),337-406.

[8] Chen. C. T. \& Hung, P. H. (2010) An Investigation on Characteristics of Affect and Growth of Students with Different Mathematics Learning Dispositions. Bulletin of Educational Psychology, 42 (1), 77-79.

[9] Claxton, G., \& Carr, M. (2004). A framework for teaching learning: The dynamics of disposition. Early Years, 24(1), 87-97

[10] Birenbaum, M., \& Nasser, F. (2006)Ethnic and gender differences in mathematics achievement and indispositions towards the study of mathematics. Learning and Instruction, $16(1), 26-40$.

[11] Dweck, C. S., \& Leggett, E. L. (1988). A social-cognitive approach to motivation and personality. Psychological review, 95 (2), 256-273.

[12] Wigfield, A., \& Cambria, J. (2010). Students' achievement values, goal orientations, and interest: Definitions, development, and relations to achievement outcomes. Developmental Review, 30(1), 1-35.

[13] Pintrich, P. R. (2000). The role of goal orientation in self--regulated learning. In M., Boekaerts, P. R., Pintrich \& M., Zeinder (Eds.), Handbook of self-regulation (pp. 451-502). San Diego, CA: Academic Press.

[14] Yan, T., Kreuter, F., \&Tourangeau, R. (2012). Latent class analysis of response inconsistencies across modes of data collection. Social science research, 41(5), 1017-1027.

[15] Muthén, L.K., \&Muthén, B.O. (1998-2012). Mplus User's Guide. Seventh Edition. Los Angeles, CA: Muthén\&Muthén.

[16] Andruff, H., Carraro, N., Thompson, A., Gaudreau, P., \&Louvet, B. (2009). Latent class growth modelling: a tutorial. Tutorials in Quantitative Methods for Psychology, 5(1), 11-24.

[17] Sourial, N.,Wolfson, C., Zhu, B., Quail, J., Fletcher, J., Karunananthan, S., Bandeen-Roche, L., Béland, F., \& Bergman, H. (2010). Correspondence analysis is a useful tool to uncover the relationships among categorical variables. Journal of Clinical Epidemiology, 63, 638-646.

[18] Crick, R. D., \& Goldspink, C. (2014).Learner Dispositions, Self-Theories and Student Engagement. British Journal of Educational Studies, 62 (1), 19-35. DOI:10.1080/00071005.2014.904038. 